Revista de Economia Política, vol. 28, $n^{\circ} 3$ (111), pp. 490-509, julho-setembro/2008

\title{
Investimento direto estrangeiro e o desempenho das exportações brasileiras
}

\author{
ELAINE APARECIDA FERNANDES \\ ANTONIO CARVALHO CAMPOS*
}

\begin{abstract}
$\sqrt{3}$
Foreign direct investment and the performance of Brazilian exports. Brazil, in the 1990s, assumed a remarkable position as a host of foreign direct investment. It is worth mentioning that the service sector received the highest proportion of foreign investment. This market seeking strategy was responsible for the growth of the Brazilian imports. The results are confirmed by the performance of foreign enterprises into different groups of activities. Those enterprises with majority of foreign capital have increased their imports the most from 1995 to 2000. Therefore, during the 1995-2000 period, this study does not support the view that foreign investment has directly improved the performance of the Brazilian exporting sector.

Keywords: Foreign direct investment, exports and transnational enterprises.

JEL Classification: F23.
\end{abstract}

A década de 1970 foi marcada por um grande afluxo de IDE para a economia brasileira. Os fatores determinantes dessa abundância na oferta de IDE estavam ligados à orientação para o crescimento econômico e à consolidação de um regime político não-discriminador do capital estrangeiro. Entretanto, durante os anos 1980, houve reversão desse fluxo de capital, determinada, entre outros fatores, pela falta de credibilidade devido ao não-cumprimento das obrigações da dívida externa, pela excessiva instabilidade econômica, pelo esgotamento do modelo de substituição de importações e pelo aumento das incertezas associadas a sucessivos planos antiinflacionários.

A partir da década de 1990 ocorre uma extraordinária recuperação do cres-

"Departamento de Economia Rural da Universidade Federal de Viçosa, Minas Gerais, e-mail: elainef1@ vicosa.ufv.br e accampos@ufv.br, respectivamente. Submetido: Agosto 2006; Aprovado: Abril 2007. 
cimento dos fluxos de IDE, que refletiu, segundo alguns autores, ${ }^{1}$ os efeitos da globalização financeira, das possibilidades de fusões e aquisições devido à abertura da economia brasileira, das privatizações e do tamanho do mercado. Essas constatações levam a constantes indagações na literatura econômica a respeito da influência do IDE na balança comercial brasileira. Nesse sentido, procura-se determinar se os investimentos diretos estrangeiros estão, de fato, contribuindo para o aumento das exportações.

Existem alguns trabalhos na literatura econômica que analisam essa questão, e os argumentos apresentados, apesar de conflitantes, podem ser divididos em duas visões. A primeira delas, considerada otimista, vislumbra a possibilidade de os fluxos de investimentos externos despertarem a indústria nacional e reativarem setores com baixo coeficiente multiplicador, além de capacitarem o país tecnologicamente. ${ }^{2}$ Nesse particular, Mendonça de Barros e Goldstein (1997) argumentam que a forte reestruturação da economia brasileira (globalização, abertura da economia, estabilização e privatização), nos anos de 1990, abriu grandes perspectivas para a entrada de novos fluxos de investimentos estrangeiros. Segundo esses autores, a lógica da globalização impõe, no entanto, que as empresas transnacionais procurem conquistar, o mais rapidamente possível, parcelas crescentes desse novo mercado ampliado (mercado brasileiro, expandido pela implementação de medidas de abertura comercial e de estabilização, acrescido pelos efeitos da consolidação do MERCOSUL). Esse comportamento implica que essas empresas apresentem, na fase inicial, um viés importador que só será amenizado com a instalação de novas plantas industriais no país. Assim, os autores apontam que os déficits acumulados no início do processo de reestruturação da economia brasileira já eram esperados.

A segunda, a visão crítica, observa que a abertura comercial e o plano de estabilização do Brasil conduziram à substituição de insumos locais por importados, bem como à desnacionalização da indústria em setores frágeis, dadas as condições desiguais de competição. ${ }^{3}$ Nesse sentido, Laplane e Sarti (1997) argumentam que as empresas transnacionais apresentam maior facilidade do que as nacionais na efetivação de transações internacionais. Assim, as empresas de capital estrangeiro são muito sensíveis à condução da política macroeconômica, principalmente a cambial, levando-as a procurarem supridores internacionais sempre que existirem condições mais favoráveis de compra nesses mercados.

De forma geral, este artigo procura fazer uma análise das estratégias de integração comercial, implementadas pelas filiais brasileiras, por meio de uma classificação fornecida por Dunning (1999), que representa padrões diferenciados des-

\footnotetext{
${ }^{1}$ Laplane e Sarti (1997), Laplane et al. (2000) e Gonçalves (1999).

${ }^{2}$ Citam-se como exemplos Moreira (1995, 1999), Balasubramanyan et al. (1996), Bonelli (1998) e Blomstrõm e Kokko (1997).

${ }^{3}$ Citam-se como exemplos Laplani e Sarti (1999); Radaelli e Furtado (2001) e Nonnenberg (2003).
} 
sa integração. Essa classificação foi feita a partir das informações de comércio e vendas de empresas individuais, para a amostra de filiais estrangeiras, nos anos de 1995 e 2000. Em seguida, procura-se, por meio da análise multivariada, identificar funções discriminantes com o intuito de verificar se a acumulação de IDE no Brasil contribuiu para aumentos significativos nas suas exportações nos períodos considerados. Especificamente, pretende-se: a) classificar os grupos de atividades setoriais segundo suas tendências comerciais; e b) determinar as participações e os efeitos dos IDEs no crescimento das exportações de grupos de atividades setoriais.

A inovação presente neste estudo refere-se ao método utilizado na investigação. Ele consiste no uso da análise multivariada discriminante para verificar a contribuição do IDE no crescimento das exportações brasileiras. Esse método é bastante adequado, já que possibilita identificar grupos de atividades que mais exportam e, ou, mais importam e, assim, fornece ferramentas de planejamento às agências governamentais na construção de políticas que possibilitem alocação do IDE de acordo com os objetivos da política econômica.

Este artigo contém, além desta introdução, mais quatro seções. Na próxima, realiza-se a tipificação das empresas estrangeiras situadas no Brasil quanto à sua tendência exportadora. Na terceira seção, faz-se a descrição do modelo. $\mathrm{Na}$ quarta, os resultados são discutidos e, finalmente, na quinta são apresentadas as principais conclusões.

\section{ESTRATÉGIAS DAS FILIAIS ESTRANGEIRAS}

Para classificar os tipos de estratégias exercidas pelas filiais de empresas estrangeiras no Brasil, utiliza-se o procedimento adotado pelo IEDI (2003), que consiste em classificar as atividades econômicas de acordo com as suas propensões a exportar e importar ${ }^{4}$. Deve-se observar que a amostra estudada é composta de filiais estrangeiras incluídas nas quinhentas maiores empresas brasileiras, publicada pela revista Exame. A Tabela 1 (na página seguinte) sintetiza os resultados encontrados para os diferentes tipos de estratégias utilizadas pelas filiais estrangeiras. Deve-se observar que a classificação está baseada em propensões médias a exportar e a importar que assumem valores iguais a 0,141 e 0,115 , respectivamente.

O primeiro tipo de estratégia é denominado resource seeking. Nesta, os empreendimentos são compostos por setores de atividade com propensão a exportar acima da média e propensão a importar abaixo da média, o que indica que são setores voltados à exportação. É de esperar que nesse grupo predominem as empresas voltadas para a exploração de setores primários ou industriais que utilizem intensivamente recursos naturais e que apresentem valores elevados para a exportação e pequenos para a importação.

\footnotetext{
${ }^{4}$ Essas variáveis serão mais bem explicadas na seção 4.1.
} 


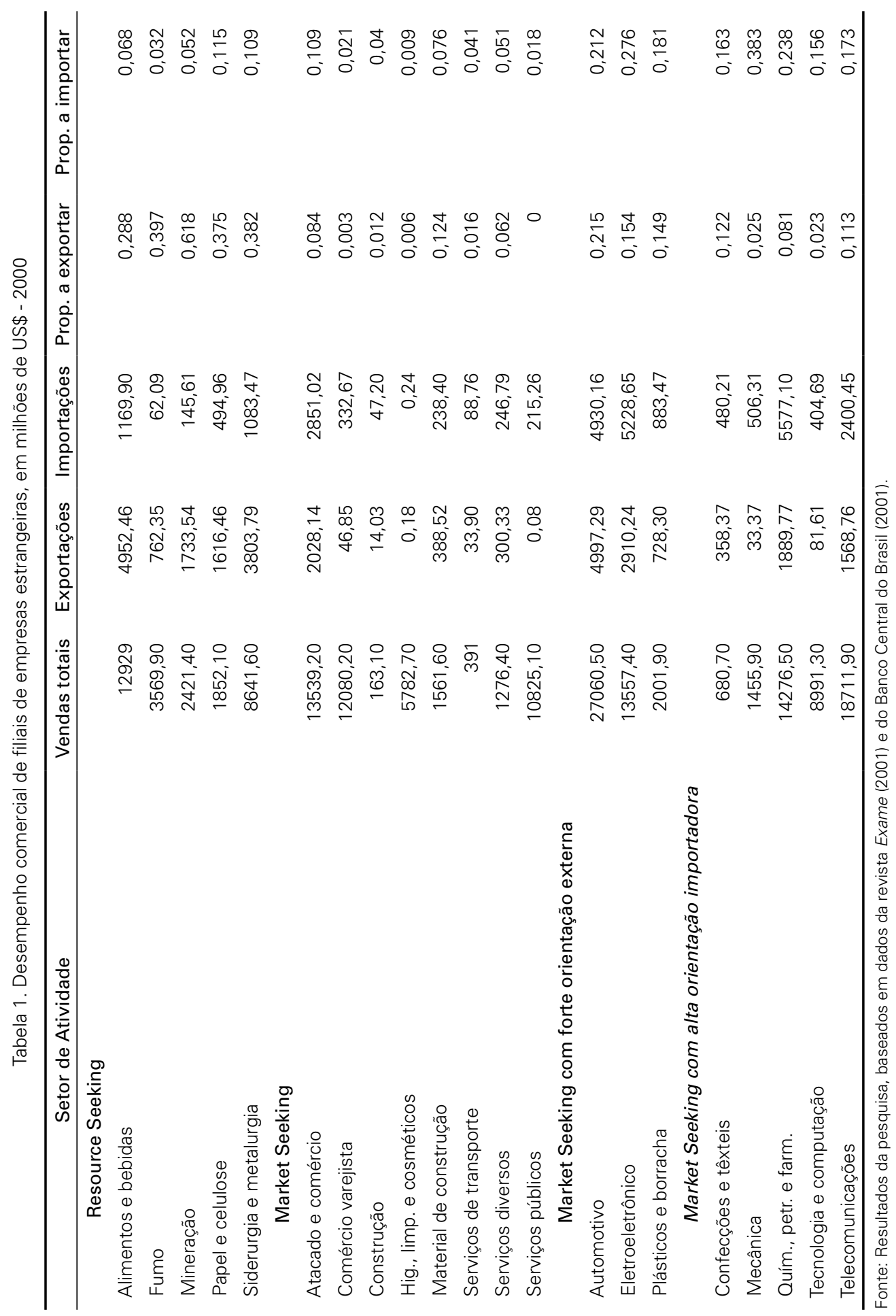


Por meio da análise dos dados, observa-se que os setores de produção de alimentos e bebidas; mineração; siderurgia e metalurgia; papel e celulose e fumo apresentaram resultados que caracterizam comportamentos voltados à exportação, com baixa orientação importadora. Esse fato sugere que os investimentos destinados a esses setores produtivos podem ser classificados tipicamente como resource seeking. É interessante notar que, exceto mineração (principalmente extração de minerais não-metálicos) e alimentos e bebidas, houve baixo acréscimo e, ou, decréscimo no estoque de IDE direcionado aos setores mencionados, quando se analisam os censos de 1995 e 2000. Siderurgia e metalurgia e papel e celulose, por exemplo, tiveram quedas equivalentes a $-16,36 \%$ e $-3,73 \%$ no estoque de IDE durante o período analisado (Tabela A3).

Em adição, como era de esperar, observa-se que as vendas voltadas para o mercado externo foram importantes e, em alguns casos, como os dos setores de alimentos e bebidas, mineração e papel e celulose, foram bem superiores àquelas voltadas ao mercado doméstico. Os cinco setores, nos quais predominam as filiais que seguem a estratégia resource seeking, caracterizam-se pela exploração de vantagens de localização, geradas pela disponibilidade e custo de recursos naturais, para colocar um volume elevado de vendas no mercado externo.

O segundo tipo de estratégia é denominado market seeking. Ela é adotada por filiais de empresas estrangeiras que desenvolvem atividades relacionadas principalmente com a produção de serviços tipicamente não-comercializáveis. Essas filiais possuem estratégias que são caracterizadas pela baixa propensão a exportar e também a importar. Os setores que fazem parte desse tipo de estratégia são os de comércio varejista; atacado e comércio; construção; higiene, limpeza e cosméticos; material de construção; serviços de transporte; serviços diversos; e serviços de utilidade pública. As vendas de todos esses setores de atividade são quase que exclusivamente destinadas ao mercado interno (Tabela 1). Esse tipo de estratégia envolve pequeno intercâmbio de mercadorias, seja no mercado regional, seja fora da região, pois apresenta baixa propensão a exportar e a importar.

Vale ressaltar que foram esses setores, voltados tipicamente para o mercado interno, que receberam os maiores fluxos de IDE. Essa afirmativa pode ser confirmada quando se analisam as variações nos estoques de IDE nos períodos censitários de 1995 e 2000. Os setores de comércio varejista e de serviços de utilidade pública destacaram-se dentre os que mais receberam IDE. No período analisado, os dois setores apresentaram taxas de crescimento de $481,81 \%$ e $2757,07 \%$, respectivamente. Os demais setores dentro do grupo, caracterizados como market seeking, também apresentaram crescimentos importantes, atingindo uma média de quase $150 \%$ (Tabela A3).

Além da classificação-padrão de Dunning, decidiu-se pela separação de outros dois grupos intermediários: market seeking com forte orientação externa e market seeking com alta orientação importadora. O primeiro caso pode ser ilustrado pelos setores automotivo, eletroeletrônico e plástico e borracha, já que suas vendas domésticas são bem superiores às suas vendas externas. Nesses setores, ocorre comportamento diferenciado da categoria market seeking puro. Esses se- 
tores apresentam orientação externa mais intensa do que a observada nos demais setores. Eles se enquadram, assim, naquelas atividades econômicas que realizam grandes transações de mercadorias tanto no mercado interno como no externo, por possuírem propensão a exportar e a importar acima da média. Nesses setores, a participação do IDE também tem crescido; entretanto, as taxas de crescimento são consideravelmente menores que nos setores classificados como market seeking puros. As taxas médias de crescimento observadas, nesses casos, não ultrapassaram 36\% (Tabela A3).

A última categoria, market seeking com alta orientação importadora, caracteriza-se pela presença de filiais de empresas estrangeiras com alta orientação importadora, mas com baixa orientação exportadora. Essas empresas também podem ser classificadas como possuidoras de estratégias market seeking, por serem suas vendas internas superiores às externas, exceto para confecção e têxteis, em que os valores quase se igualam. Os setores de mecânica; confecções e têxteis; química, petroquímica e farmacêuticos; tecnologia e computação; e telecomunicações podem ser citados como exemplos. Esses setores são chamados deficitários, por possuírem o quantum importado muito superior ao do exportado, já que são altamente dependentes de insumos importados.

É exatamente nesses setores deficitários que se encontra o setor de telecomunicações, um dos mais significativos para o crescimento do estoque de IDE no Brasil no período do estudo. O estoque de IDE nesse setor apresentou crescimento extraordinário $(4605,24 \%)$ no período compreendido entre os anos de 1995 e 2000. Outros setores deficitários que apresentaram altas taxas de crescimento foram: mecânica e tecnologia e computação, que aumentaram os respectivos estoques de IDE em $408,43 \%$ e $176,69 \%$. Os setores de confecções e têxteis e química, petroquímica e farmacêuticos experimentaram taxas de crescimento menos expressivas, porém aumentaram também seu estoque de IDE (Tabela A3).

Como observado, foram realizados vários investimentos nesses setores na última década, os quais possibilitaram fortes impactos na eficiência das filiais e dos serviços prestados por elas. Os ganhos de produtividade, entretanto, não se materializaram em saldos comerciais positivos em termos setoriais. As filiais dessas empresas estrangeiras instaladas no Brasil continuam a desempenhar um papel local e, ou, regional. As baixas propensões a exportar mostram que essas empresas não realizam exportações significativas diretamente, mas podem estar contribuindo para o melhor desempenho de outros setores exportadores. Dessa forma, o objetivo dos governantes brasileiros em atrair capital estrangeiro para gerar saldos positivos na balança comercial não foi atendido de modo pleno, no período considerado.

\section{REFERENCIAL TEÓRICO}

$\mathrm{Na}$ tentativa de explicar os fluxos de IDE sob as perspectivas das teorias pura do comércio internacional e da organização industrial, Vernon (1971, 1974 e 1979), 
Hymer (1960, 1976, 1990) e Dunning (1981, 1988, 1993, 1999), entre outros, apresentaram a evolução da teoria do comércio internacional associada à teoria do investimento direto estrangeiro, que, até então, eram vistas isoladamente.

No que se refere especificamente à exportação, Hirsch (1976) procurou fazer uma ligação entre o fluxo de comércio e o IDE. Seu modelo parte da constatação de que, sob os pressupostos neoclássicos, só haveria lugar para o IDE se houvesse diferencial de taxas de juros. No entanto, na presença desse diferencial de juros, provavelmente, predominariam as formas de investimentos em portfólio e no crédito internacional. Assim, Hirsch introduz novos pressupostos no modelo para que o IDE voltado à formação do estoque de capital físico fosse viável. Esses pressupostos dizem respeito à existência de diferentes funções de produção e de custos entre os países, vantagens específicas para algum tipo de empreendimento, barreiras à entrada e custos diferenciados para a coordenação das atividades internacionais das empresas.

Considere que as variáveis a seguir sejam assim definidas.

$\mathrm{C}$ - representa o custo de produção no país de origem;

$\mathrm{C}^{*}$ - representa o custo de produção no país de implantação;

$\mathrm{M}^{*}$ - representa o custo de importação, incluindo seguros, transportes, tarifas e outros custos de transação e marketing;

$\mathrm{K}^{*}$ - representa o custo da criação ou de aquisição de know-how e de outros ativos privados intangíveis;

$A^{*}$ - representa o custo de informação e controle operacional em ambiente diferente do país de origem; e

$D^{*}$ - representa o custo de dissipação dos conhecimentos e de outras vantagens privadas, além do custo de transferência de tecnologia.

Diante do ambiente econômico influenciado por essas variáveis, a filial de uma empresa estrangeira tem três opções para expandir o seu mercado.

1) Opção pela exportação

Esta opção será considerada quando:

$\mathrm{C}+\mathrm{M}^{*}<\mathrm{C}^{*}+\mathrm{A}^{*} \mathrm{e}<\mathrm{C}^{*}+\mathrm{K}^{*} \rightarrow$ exportação versus IDE.

$\mathrm{C}+\mathrm{M}^{*}<\mathrm{C}^{*}+\mathrm{D}^{*} \rightarrow$ exportação versus licenciamento.

2) Opção pelo IDE

$\mathrm{C}^{*}+\mathrm{A}^{*}<\mathrm{C}+\mathrm{M}^{*}$ e $<\mathrm{C}^{*}+\mathrm{K}^{*} \rightarrow$ IDE versus exportação.

$\mathrm{C}^{*}+\mathrm{A}^{*}<\mathrm{C}^{*}+\mathrm{D}^{*} \rightarrow$ IDE versus licenciamento.

3) Opção pelo licenciamento

$\mathrm{C}^{*}+\mathrm{D}^{*}<\mathrm{C}^{*}+\mathrm{A}^{*} \rightarrow$ licenciamento versus IDE.

$\mathrm{C}^{*}+\mathrm{D}^{*}<\mathrm{C}^{*}+\mathrm{M}^{*} \rightarrow$ licenciamento versus exportação.

A situação caracterizada como $\mathrm{M}^{*}=\mathrm{K}^{*}=\mathrm{A}^{*}=\mathrm{D}^{*}=0$ corresponde ao paradigma neoclássico de mercados perfeitos para produtos e fatores de produção.

Esse modelo não leva em consideração o IDE com o objetivo de abastecer o mercado de origem das transnacionais. Com base nessa deficiência, Rugman et al. 
(1985) reorganizam o modelo de Hirsch, partindo do princípio de que o mercadoalvo não é o estrangeiro, mas sim o próprio mercado nacional do país de origem das empresas transnacionais. Nesse caso, tem-se:

1) Opção pela produção doméstica

$\mathrm{C}<\mathrm{C}^{*}+\mathrm{M}+\mathrm{A}^{*} \mathrm{e}<\mathrm{C}^{*}+\mathrm{M}^{*}+\mathrm{D}^{*}$

2) Opção pelo IDE

Esta opção significa que o bem será produzido no estrangeiro (país anfitrião) e importado pelo país de origem da empresa transnacional.

$\mathrm{C}^{*}+\mathrm{M}+\mathrm{A}^{*}<\mathrm{C}$ e $<\mathrm{C}^{*}+\mathrm{M}+\mathrm{D}^{*}$

3) Opção pelo licenciamento

Neste caso, importa-se a produção do país que fez o licenciamento.

$C^{*}+M+D^{*}<C^{*}+M+A^{*} e<C$

Dessa forma, conhecendo essas relações, pode-se especificar a função discriminante de modo a estabelecer o relacionamento entre o IDE e os grupos com características discriminadoras.

\section{ESTIMAÇÃO DA FUNÇÃO DISCRIMINANTE}

\section{Classificação dos grupos}

Primeiramente, com base no procedimento utilizado pelo IEDI (2003), classificam-se as atividades econômicas de acordo com as suas propensões a exportar e importar (equações 1 e 2). A partir daí, quatro grupos são selecionados conforme a importância relativa das exportações e importações para as operações dessas atividades. ${ }^{5}$

$$
\begin{aligned}
& P X=\frac{X}{R O L}, \\
& P M=\frac{M}{R O L},
\end{aligned}
$$

em que PX e PM são, respectivamente, as propensões a exportar e importar do conjunto de empresas de cada setor; $\mathrm{X}$ as exportações (FOB); $\mathrm{M}$, as importações (FOB); ${ }^{6}$ e ROL, a receita operacional líquida.

O primeiro grupo é composto por setores com propensão a exportar acima

\footnotetext{
${ }^{5}$ São definidos quatro grupos, entretanto, na análise discriminante são usados apenas dois (propensões a exportar abaixo e acima da média), já que o objetivo é verificar o impacto do IDE no valor das exportações brasileiras.

${ }^{6}$ Foram utilizadas importações a preço FOB e não CIF, devido ao fato de os censos de capitais estrangeiros somente informarem valores FOB.
} 
da média e propensão a importar abaixo da média, o que indica que são setores voltados para a exportação (setores superavitários - SS). É de esperar que nesse grupo predominem os setores primários ou industriais que utilizem intensamente recursos naturais e, em geral, apresentem valores elevados de exportação e valores pequenos de importação.

Os chamados setores deficitários (SD) compõem o segundo grupo. Formado por setores com propensão a exportar abaixo da média e a importar acima da média, sua principal característica é possuir volume importado superior ao exportado. Deve ser representado, em grande parte, por setores industriais demandantes de insumos importados, como, por exemplo, o setor químico, de material eletrônico e de comunicações e equipamento de informática.

O terceiro grupo é composto por setores que possuem baixa propensão a exportar e importar, tanto em termos absolutos quanto em relação à receita. Esses setores são chamados de baixo comércio (SBC) e, em geral, são setores de serviços, tipicamente non-tradables.

O quarto grupo engloba setores de elevado comércio (SEC), o que indica que suas propensões a exportar e a importar estão acima da média. Espera-se que esse grupo seja composto, em sua maioria, por setores industriais com grandes volumes de transações comerciais, embora com pequenos saldos comerciais, positivos ou negativos.

\section{Determinação da função discriminante}

O passo seguinte consiste na estimação da função discriminante, devendo-se, para isso, especificar os grupos que serão utilizados na análise. Embora quatro grupos tenham sido definidos na seção anterior, apenas dois serão usados na realização da análise discriminante. Esses dois grupos representam os setores de atividade com propensões a exportar abaixo e acima da média, respectivamente.

A análise discriminante permite elaborar uma "regra" (função) de discriminação de grupos, objetos, itens ou indivíduos com base em um grande número de variáveis. Seu principal objetivo é encontrar uma ou mais funções que sejam capazes de efetuar a discriminação entre os grupos. Assim, a análise discriminante inicia-se a partir de grupos previamente definidos e investiga qual variável possui maior poder de discriminação entre eles (Hair et al., 1995). Este método permite que se crie uma ou mais variáveis $\mathrm{Y}$, que representam uma combinação linear ${ }^{7}$ das variáveis que servem de base para a análise. Desse modo, $\mathrm{Y}_{\mathrm{i}}$ é a função discriminante, que assume a seguinte forma:

$$
Y_{i}=\alpha_{1} X_{1 i}+\alpha_{2} X_{2 i}+\ldots+\alpha_{3} X_{m i}
$$

em que $\mathrm{Y}_{\mathrm{i}}$ são os escores da variável binária $\mathrm{Y}$. Essa variável assume valor 1

\footnotetext{
${ }^{7}$ Um dos motivos de se ter utilizado uma função linear consiste em sua forma simples e interpretação clara dos efeitos de cada variável independente. Para mais detalhes, ver Morrison (1969).
} 
para grupos que possuem propensão a exportar abaixo da média e valor 2 para os que possuem propensão a exportar acima da média. Em seguida, têm-se os $\alpha_{\mathrm{i}}$, que são os coeficientes ponderados cujos valores são estimados pelo método discriminante, e, por último, os $\mathrm{X}_{\mathrm{ji}}$, que são as variáveis que servem como discriminadoras entre os grupos de elementos, para os quais os escores são computados. Neste estudo, as variáveis $\mathrm{X}_{\mathrm{ji}}$ são representadas pela receita operacional líquida - ROL, imposto de renda e contribuições - IRC, patrimônio líquido - PL, ativo - A e estoque de IDE - EIDE. Idealmente, espera-se que os escores estimados sejam, razoavelmente, semelhantes para os setores pertencentes a um mesmo grupo.

A função discriminante é estimada de forma a maximizar a separação entre os grupos (heterogeneidade) e a igualdade dentro de cada grupo (homogeneidade) a partir da equação:

$$
\left|M^{-1} A-I \lambda\right|=0,
$$

em que: $\mathrm{M}$ é a matriz intergrupos; A, matriz de dispersão intragrupos; e $\lambda$, as raízes características de $M^{-1} A$.

Deve-se destacar que essas funções são extraídas em ordem decrescente de importância, o que significa que a primeira função é a que extrai o máximo da variância intergrupos, a segunda extrai a variância remanescente e assim sucessivamente. Associada a cada função existe uma raiz característica, que representa a porção da variância total intergrupos explicada pela função.

Para aplicação de testes de significância às funções discriminantes lineares, os seguintes pressupostos devem ser observados:

a) As observações em cada grupo são escolhidas ao acaso.

b) A probabilidade de um indivíduo desconhecido pertencer a um dos grupos é a mesma.

c) As variáveis discriminantes têm distribuição normal.

d) As matrizes de co-variâncias dos grupos são iguais.

e) As populações diferem quanto às médias.

\section{Fonte dos dados}

$\mathrm{Na}$ construção dos indicadores das propensões a exportar e a importar foram utilizadas informações referentes ao ano 2000, contidas na revista Exame e no Banco Central. As séries de receita operacional líquida - ROL, imposto de renda e contribuições - IRC, patrimônio líquido - PL, ativo - A e estoque de IDE EIDE foram obtidas através dos censos de capitais estrangeiros para 1995 e 2000, divulgados pelo Banco Central. Em 1995, existiam 6.322 empresas com participação de capital estrangeiro. Em 2000, esse número atinge 11.404 empresas. Segundo classificação do Banco Central do Brasil (2001), empresas com participação estrangeira são instituições sediadas no país com participação direta ou indireta de não-residentes em seu capital social de, no mínimo, $10 \%$ das ações ou quotas com direito a voto ou $20 \%$ de participação direta ou indireta no capital total. Empresas 
com participação majoritária estrangeira são aquelas de cujo capital social participam não-residentes com mais de 50\% do capital votante. Em 1995, elas eram de 4.902 declarantes e, em 2000, esse número subiu para 9.712 declarantes.

\section{ANÁLISE DOS RESULTADOS}

\section{Análise das propensões médias a exportar e a importar}

Inicialmente, fez-se o cálculo das propensões médias a exportar e a importar no intuito de classificar as atividades, assim como verificar o efeito transbordamento (spillover) exercido pelo IDE nas exportações brasileiras em 1995 e 2000. Os resultados podem ser visualizados nas Tabelas A1 e A2.

Como era esperado, no grupo 1 predominaram os setores primários ou industriais que utilizam intensivamente recursos naturais; no grupo 2, setores industriais demandantes de insumos importados; no grupo 3, setores non-tradables, como o setor de serviços; e, no grupo 4, setores industriais com volumes significativos de comércio.

Uma análise preliminar dos fluxos de IDE para esses quatro grupos (IEDI, 2003) mostra que, de todo o IDE acumulado entre 1996 e 2001, 60,2\% direcionaram-se para setores de atividade com baixa inserção comercial externa. Deve-se destacar que a participação desse grupo no total das exportações das empresas estrangeiras situou-se em torno de $9 \%$, enquanto participou com $14 \%$ no total das importações dessas empresas. O grupo dois (setores deficitários) abarcou $25 \%$ do total do fluxo de IDE no mesmo período. Por sua vez, esse grupo participou com $15,1 \%$ nas exportações e quase $50 \%$ nas importações.

O grupo um, formado por setores com alta propensão a exportar, participou com $38,8 \%$ no total das exportações das empresas estrangeiras e com $9 \%$ nas importações, tendo recebido pouco mais de 6\% do IDE acumulado entre $1996 \mathrm{e}$ 2001. O mesmo resultado foi observado para o grupo com maior volume de comércio (grupo quatro), que é formado por setores com alta participação tanto na exportação $(36,8 \%)$ quanto na importação $(34 \%)$.

Diante do exposto, observa-se que os setores voltados para as exportações e para maior grau de comércio têm recebido, relativamente, menos IDE na formação de seu capital físico. De forma contrária, os setores deficitários e de baixo nível comercial com o exterior abarcaram as maiores quantidades desse fluxo de IDE, o que sugere, de forma antecipada, ausência do efeito positivo direto dos investimentos externos no aumento das exportações brasileiras. Entretanto, é importante ressaltar que houve crescimento nas propensões médias tanto a exportar como a importar quando se consideraram os dois períodos do censo (1995 e 2000 - Tabela 2). Contudo, o maior crescimento observado foi na propensão a importar, com variação de $61,36 \%$ contra $33,85 \%$, observado na propensão a exportar. Isso significa que a maior participação de IDE na economia brasileira, verificada por meio do censo de capitais de 2000, contribuiu, em sua maior parte, para au- 
mentar as importações e não as exportações. Assim, o efeito spillover ocorreu nas importações e não nas exportações, como era o desejado.

Tabela 2: Propensões médias a exportar e importar da economia brasileira nos anos de 1995 e 2000

\begin{tabular}{lcc}
\hline & \multicolumn{2}{c}{ Propensões médias } \\
\hline & \multicolumn{1}{c}{ Exportar } & Importar \\
\cline { 2 - 3 } 1995 & 0,105254704 & 0,071060539 \\
2000 & 0,140884368 & 0,114661039 \\
Taxa de Crescimento (\%) & 33,85 & 61,36 \\
\hline
\end{tabular}

Fonte: Resultados da pesquisa.

\section{Cálculo da função discriminante}

O cálculo da função discriminante para os grupos com propensões a exportar abaixo e acima da média é realizado com os dados das propensões a exportar das atividades selecionadas (Tabela A2). Nesse caso, o número de grupos resume-se a dois: aqueles com propensão a exportar acima da média e aqueles com propensão a exportar abaixo da média. As variáveis utilizadas na análise foram: estoque total de IDE, patrimônio líquido, receita operacional líquida, imposto de renda e contribuições e o ativo da empresa. Como são dois grupos e cinco variáveis, existe a possibilidade da existência de apenas uma função discriminante ${ }^{8}$ (Tabela 2).

Deve-se ressaltar que apenas a média da variável imposto de renda e contribuições foi diferente nos dois grupos analisados. As demais variáveis, inclusive o estoque de IDE, apresentaram valores médios estatisticamente iguais para os grupos considerados. Diante disso, essas variáveis poderiam ter sido retiradas da análise; todavia, foram mantidas com o objetivo de retratar a irrelevância do IDE para o aumento das exportações brasileiras quando se considera a participação estrangeira total.

Os resultados (Tabela 3) indicam que o valor $\lambda$ de Wilks foi de 0,52 , significando que a função serve para separar os dois grupos, já que os valores de $\lambda$ devem variar entre zero e um. Observa-se que, quanto menor for esse coeficiente, melhor será a função. Do mesmo modo, o qui-quadrado foi igual a 54,41, indicando que a função discriminante foi significativa a $5 \%$ de probabilidade. Quanto ao grau de previsão do modelo, as estatísticas foram satisfatórias, ficando o percentual de classificação correta em torno de 76,3\%.

\footnotetext{
${ }^{8} \mathrm{O}$ número de funções discriminantes é determinado pelo min \{parâmetros, número de grupos -1 \}.
} 
Tabela 3: Função discriminante padronizada para as variáveis selecionadas

\begin{tabular}{ccc}
\hline Variáveis & 1. Coeficientes & 2. Teste $\mathrm{F}$ \\
\hline Receita operacional líquida & 0,11 & $0,48 \mathrm{~ns}$ \\
Imposto de renda e contribuições & $-1,31$ & $3,99^{* *}$ \\
Patrimônio líquido & 1,46 & $0,09 \mathrm{~ns}$ \\
Ativo & 1,13 & $0,33 \mathrm{~ns}$ \\
Estoque de IDE total & 1,14 & $0,30 \mathrm{~ns}$ \\
$\lambda$ de Wilks & \multicolumn{2}{c}{0,52} \\
Qui-quadrado & $54,41^{* *}$ \\
\hline
\end{tabular}

Fonte: Resultados da pesquisa.

* significativo a $5 \%$.

Utilizando-se da função discriminante para atribuir escores às atividades (Tabela A4), pode-se testar a classificação anteriormente feita pela propensão a exportar. Observa-se que a classificação feita pela função discriminante praticamente coincidiu com a que foi feita usando-se a propensão a exportar. As exceções foram os casos das atividades de silvicultura, exploração florestal e serviços relacionados; pesca, aqüicultura e serviços relacionados; extração de minerais não-metálicos; preparação de couros, fabricação de artefatos e calçados; fabricação de produtos de madeira; fabricação de coque, petróleo, combustíveis nucleares e álcool; fabricação de artigos de borracha e plástico; fabricação de produtos minerais nãometálicos; fabricação de produtos de metal; fabricação de máquinas, aparelhos e materiais elétricos; fabricação de material eletrônico e equipamentos de comunicação; atividades auxiliares da intermediação financeira; e atividades de informática e conexas.

As discrepâncias preditivas mais sérias ocorreram com as atividades pesca, aqüicultura e serviços relacionados; preparação de couros, fabricação de artefatos e calçados; fabricação de produtos de madeira e fabricação de produtos minerais não-metálicos, pois a probabilidade de essas atividades pertencerem a um grupo equivocado foi superior a $60 \%$. Nos demais casos, embora as probabilidades indiquem que a classificação anterior estava errada, a situação em termos de probabilidades não é tão óbvia, sendo as chances de pertencer a um ou outro grupo quase as mesmas.

A função discriminante padronizada (Tabela 3) mostra que a única variável importante para discriminar os grupos de quem possui maior propensão a exportar é o imposto de renda e contribuições. Nesse sentido, quanto menor for o valor cobrado do imposto, maior a quantidade exportada pelo conjunto de firmas com participação estrangeira, pois essa variável discrimina em favor da propensão a exportar acima da média. Essa constatação pode ser resultado do crescimento da carga tributária sobre o produto dessas empresas. A carga de impostos, taxas e contribuições cobradas sobre a geração de riqueza das maiores empresas em atividade no país (estrangeiras ou não) aproxima-se de 50\%. Esse valor é extre- 
mamente elevado e somente pode ser comparado aos cobrados em países como Japão e Alemanha (países ricos, onde a carga tributária somente aumentou após o enriquecimento da sociedade).

De forma contrária, a quantidade de IDE não possui qualquer relação na distinção entre os grupos, o que sugere que seu montante não está relacionado com o crescimento das quantidades exportadas. Esse resultado pode ser conseqüência da destacada participação do setor de serviços no fluxo total de IDE na década de 1990 e, também, pelo fato de as filiais estrangeiras se direcionarem ao Brasil visando, principalmente, ao mercado interno.

\section{CONCLUSÕES}

Durante a década de 1990, aumentou consideravelmente a participação de empresas transnacionais na economia brasileira. Os resultados deste estudo mostram que as estratégias das empresas estrangeiras voltadas para os setores de alimentos e bebidas; mineração; siderurgia e metalurgia; papel e celulose; e fumo tiveram comportamentos direcionados para a exportação, com baixa orientação importadora. Esse fato sugere que os investimentos nesses setores podem ser classificados tipicamente como resource seeking.

É interessante notar, ainda, quando se analisam os censos de 1995 e 2000, que, exceto nas atividades de mineração (principalmente extração de minerais não-metálicos) e alimentos e bebidas, houve pequeno crescimento e, ou, decréscimo no estoque de IDE direcionado ao setor de manufaturados. Como era de esperar, devido à escassez de divisas, as vendas direcionadas ao mercado externo foram elevadas e, em alguns casos, como as vendas dos setores de alimentos e bebidas, mineração e papel e celulose, bem superiores àquelas voltadas ao mercado doméstico.

As filiais de empresas estrangeiras que desenvolvem atividades relacionadas com o setor de serviços, tipicamente produtoras de bens não-comercializáveis, com estratégias market seeking, apresentaram participação crescente nos setores: comercial (varejista e atacado), construção, higiene, limpeza e cosméticos, material de construção, serviços de transporte, serviços diversos e serviços públicos. As vendas desses setores supracitados são quase que exclusivamente voltadas ao mercado interno. Esse tipo de estratégia envolve pequeno intercâmbio de mercadorias, seja no mercado regional, seja fora da região, pois apresenta baixas propensões a exportar e a importar. Vale ressaltar que são esses setores, voltados tipicamente para o mercado interno, que receberam maiores fluxos de IDE.

No que diz respeito às propensões a exportar e importar, este estudo corrobora os resultados contidos em IEDI (2003), em que os setores com maiores capacidades exportadoras ou alto volume de comércio são os que menos têm recebido fluxos de IDE. Por sua vez, os setores com baixa expressão nas exportações ou importações e os setores deficitários são os que têm recebido o maior volume desses fluxos de investimentos. Em termos do equilíbrio externo, esse comportamento 
torna-se preocupante, visto que os setores de maior destino dos fluxos de IDE não possuem relação positiva com o crescimento das exportações.

A análise discriminante deixa claro que a única variável importante para discriminar os grupos, dentre as analisadas, é o imposto de renda e contribuições. De forma contrária, o volume de IDE não possui qualquer relação na distinção entre os grupos, o que sugere que seu montante não está relacionado com maiores quantidades exportadas. Esse resultado confirma a análise fundamentada nas propensões a exportar e a importar, o que gera dúvidas a respeito da eficácia da política de atração do IDE para o Brasil, no contexto econômico do período analisado.

Entretanto, deve-se ressaltar que não basta colocar empecilhos à entrada desse tipo de investimento devido à sua baixa contribuição direta para o crescimento das exportações, principalmente se estiverem associados à criação de novas vantagens competitivas, a projetos de exportação e ao aumento da capacidade de produtiva. Assim, devem-se adotar medidas de política industrial dentro da nova perspectiva de concorrência internacional, vigente a partir da abertura da economia brasileira, que redirecionem o fluxo de IDE para setores com maior participação no comércio exterior e que contribuam efetivamente para aumentar o crescimento das exportações e, conseqüentemente, fazer face às necessidades de importações.

\section{REFERÊNCIAS BIBLIOGRÁFICAS}

BANCO CENTRAL DO BRASIL. Censo de Capitais Estrangeiros. Acesso em: 13 de junho de 2004. (http://www.bacen.gov.br).

BALASUBRAMANYAM, V.N., SALISU, M.; SAPSFORD, D. Foreign Direct Investment and Growth in EP and IS Countries. The Economic Journal, v. 106, pp. 92-105. 1996.

BLOMSTROM, M.; KOKKO, A. How Foreign Investment Affects Host Countries. NBER Working Paper, n. 1745, 1997.

BONELLI, R. A Note on Foreign Direct Investment (FDI) and Industrial Competitiveness in Brazil. Texto para Discussão, IPEA, n. 584, 1998.

DUNNING, J.H. International Production and the Multinational Enterprise. London: George Allen \& Unwin, 1981.

DUNNING, J.H. Explaining International Production. London: London Unwin Hyman, 1988.

DUNNING, J.H. Multinational Enterprises and the Global Economy. New York Addison-Wesley. 1993.

DUNNING, J.H. Globalization and the Theory of MNE Activity. Discussion Papers in International Investment and Management, n. 264, Department of Economics, University of Reading, 1999.

GONÇALVES, R. Globalização e Desnacionalização. Rio de Janeiro: Paz e Terra, 1999.

HAIR Jr. J.; ANDERSON, R.; TATHAM, R.; BLACK, W. Multivariate Data Analysis. New Jersey Ed. Prentice Hall,: 1995.

HIRSCH, S. An International Trade and Investment Theory of the Firm. Oxford Economic Papers, 28 julho, pp 258-270, 1976.

HYMER, S.H. The International Operations of National Firms, Cambridge, Mass.: The MIT Press. 1960.

HYMER, S.H. The International Operations of National Firms: A Study of Direct Foreign Investment, Boston: The Press, 1976.

HYMER, S.H. The Large Multinational Corporation: An Analysis of Some Motives for the Inter- 
national Integration of Business. In: Mark Casson (ed.) Multinational Corporations, Aldershot Edward Elgar,: 1990.

IEDI. O Investimento Estrangeiro na Economia Brasileira e o Investimento de Empresas Brasileiras no Exterior. Acesso em: 15 de março de 2004. (http://.www.iedi.com.br).

LAPLANE, M. F.; SARTI, F. O Investimento Direto Estrangeiro no Brasil nos Anos 90: Determinantes e Estratégias. Revista do Instituto de Economia da Unicamp, n. 8, 1997.

LAPLANE, M.; SARTI, F. Investimento Direto Estrangeiro e o Impacto na Balança Comercial nos Anos 90. Texto para Discussão, n. 629, Brasília, IPEA, 1999.

LAPLANE, M.; SARTI, F.; HIRATUKA, C.; SABBATINI, R. Internacionalização e Vulnerabilidade Externa. In LACERDA, A. C. (Org.) Desnacionalização: mitos, riscos e desafios. São Paulo: Contexto, 2000.

MEDONÇA DE BARROS, J.R.; GOLDSTEIN, L. Avaliação do Processo de Reestruturação Industrial Brasileira. Revista de Economia Política, v. 17, n. 2, pp. 11-31, 1997.

MOREIRA, M.M. Industrialization, Trade and Market Failures: the role of government intervention in Brazil and South Korea. London: Macmillan Press, 1995.

MOREIRA, M.M. Estrangeiros em uma Economia Aberta: Impactos Recentes sobre Produtividade, Concentração e Comércio Exterior. Texto para Discussão, BNDES, n. 67, março de 1999.

MORRISON, D.G. On the Interpretation of Discriminant Analysis. Journal of marketing research, v. 6, pp. 156-63, 1969.

NONNENBERG, M.J. Determinantes dos Investimentos Externos e Impactos das Empresas Multinacionais no Brasil — as Décadas de 1970 e 1990. Texto para Discussão, IPEA, n. 969, 2003.

RADAELLI, V.; FURTADO, J. Investimento Direto Estrangeiro na Indústria no Brasil no Período Recente: uma Análise a partir de um Grupo de Empresas Internacionais. Acesso em: 13 de junho de 2004. (http://.www.fclar.unesp.br/pesq/grupos/geein/html).

REVISTA EXAME. Melhores e Maiores. São Paulo: abril-julho de 2001.

RUGMAN, A.; DONALD, J.L.; LAURENCE, D. International Business: Firm and Environment. New York: McGraw-Hill, 1985.

VERNON, R. Foreign Trade and Foreign Investment: Hard Choices for Developing Countries. Foreign Trade Review, January-March, 1971.

VERNON, R. The Location of Economic Activity. In: John H. Dunning (Ed.) Economic Analysis and the Multinational Enterprise. London: George Allen \& Unwin, 1974.

VERNON, R. The Product Cycle Hypothesis in the new International Environment. Oxford Bulletin of Economics and Statistics, v. 41, pp. 255-67, November, 1979. 


\section{APÊNDICE}

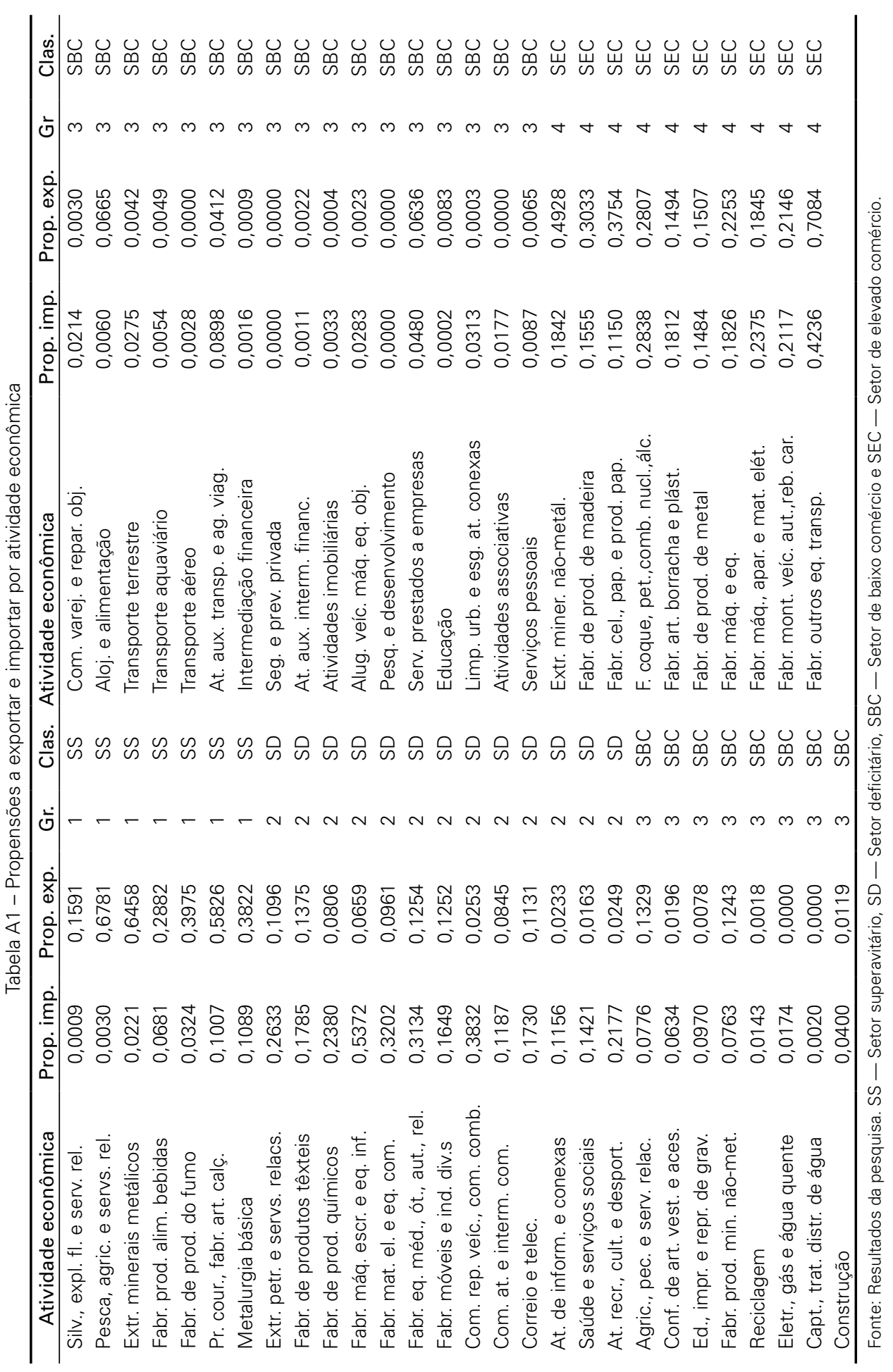




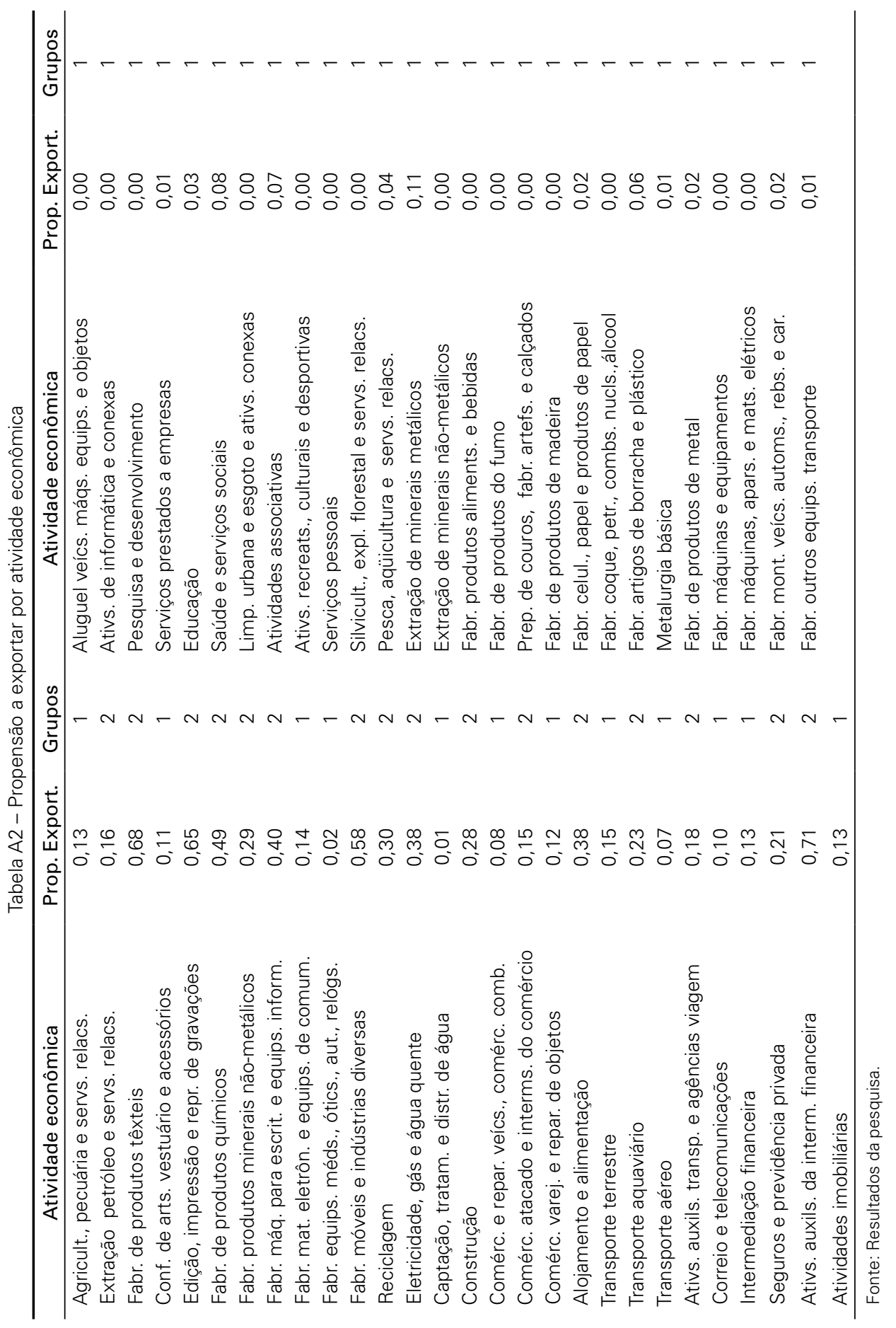




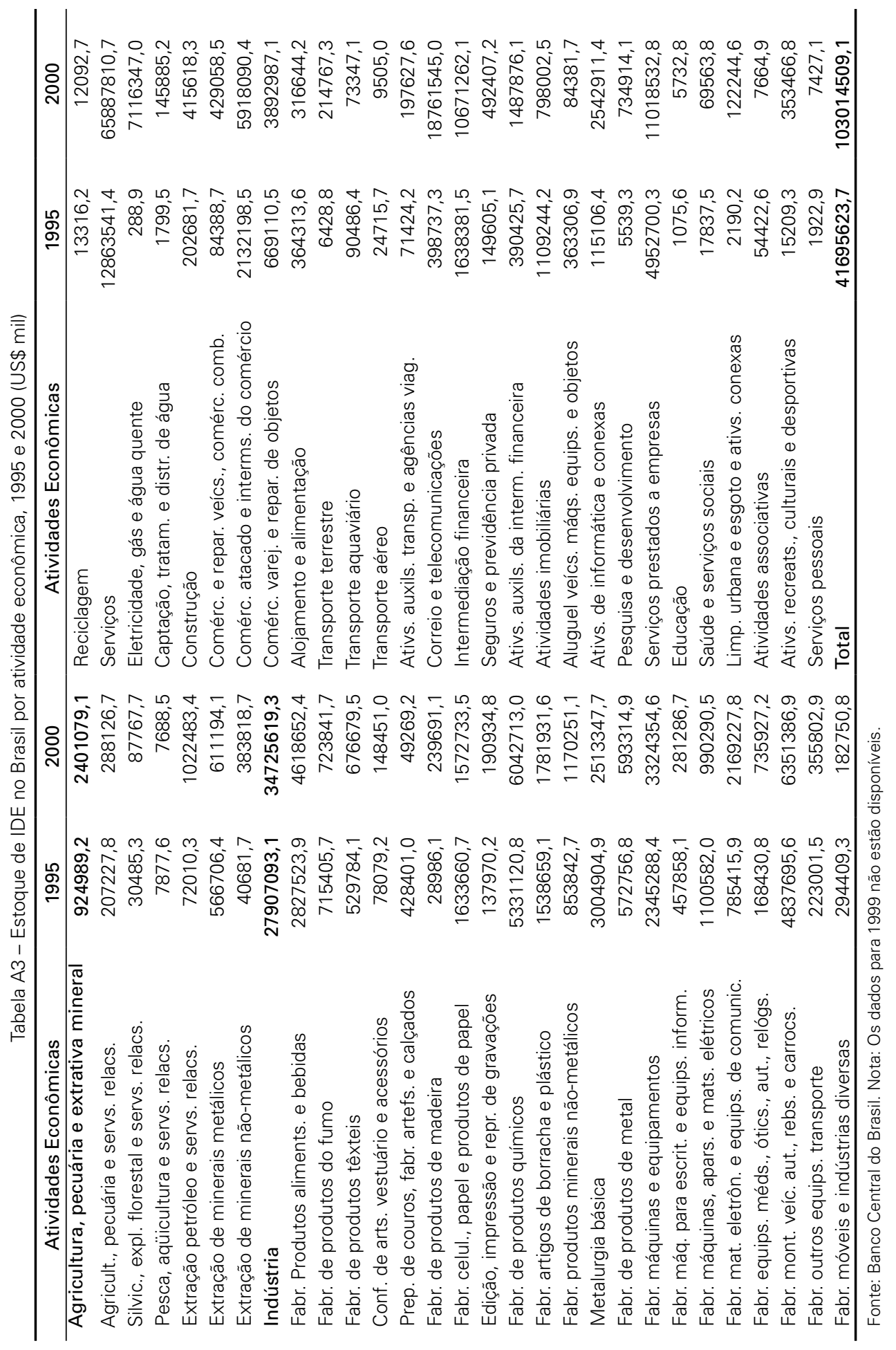




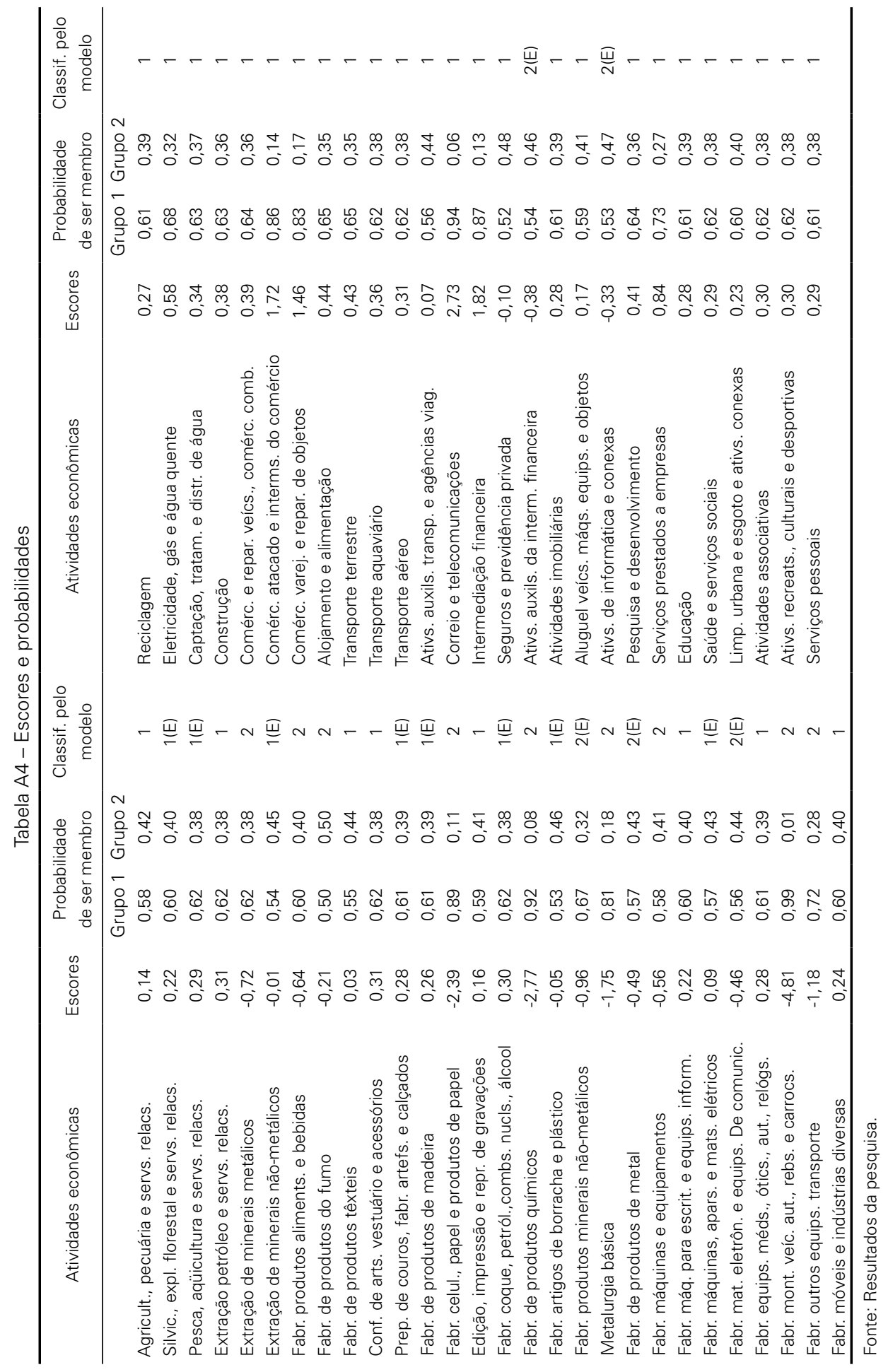

